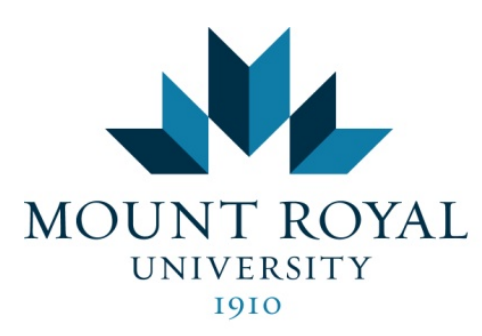

Mount Royal Undergraduate Education Review
Department of Education and Schooling

Volume 1(1)

Spring 2014

\title{
Maximizing student experience in mathematics: Traditional tools versus digital technologies
}

Cassandra Luckwell, Mount Royal University

\begin{abstract}
This study was created to find out the tools that encourage and maximize student learning in mathematics, what causes positive and negative experiences in mathematics, and can any of these tools and experiences be replaced by digital technologies. I gathered an assortment of information through online surveys, interviews and field notes. My main findings showed that most people think that math manipulatives, direct teaching, and hands on learning were very important to their learning and help to decrease negative experiences in math. Furthermore, positive experiences were created through teacher feedback and encouragement and when students could relate what they were learning to their life experiences. My findings show that teachers need to be a positive model and create positive experiences for students. Moreover, teachers need to use traditional hands on tools for students and then use digital technologies as an assistive tool for further clarification and understanding.
\end{abstract}




\section{Introduction}

There has always been a stigma associated with mathematics in schools and life. This became further noticeable as I attended Mount Royal University and entered the Bachelor of Education Program with a Minor in Mathematics. This has encouraged me to do research to look at ways of improving the interest of children regarding mathematics. I am also interested to further my knowledge in ways of improving mathematics for my own future students. It is important that teachers understand the responsibility they have of teaching students the important basic skills in math that are carried through all aspects of life and they need to be a positive role model when teaching math. Math is all around us and if perceptions change and teachers can make math relevant it will help change the mind set. I would like to find different resources to help teachers, students, and parents in order to enhance student interest and understanding in math. I am going to find out the tools that encourage and maximize student learning in mathematics, what causes positive and negative experiences in mathematics, and I am questioning whether any of these tools and experiences should be replaced by digital technologies. This research will help in my future practice when it comes to finding tools that work for students; whether they are digital or not. Furthermore, it will aim at giving other teachers different potential resources they could use to facilitate a variety of learners.

\section{Background}

There is not enough emphasis put on the importance of mastering math skills. Many elementary students and teachers are not interested in mathematics and by having teachers that are negative about teaching mathematics, makes the situation worse. Jarvis \& Naested (2012) state "there is a lot of avoidance and phobias around the area of math" (p. 24). These views can be changed with the help of resources and by proving the relevance and importance of 
mathematics. It is important to try and get rid of the stigma so no one is afraid of a skill that is regularly used in life.

One way of getting rid of the stigma and gaining support in the area of mathematics is by proving its relevance to real life and integrating math into other subject areas. This will help "the current discussion [which] is making math meaningful, rather than having formulas and not being able to relate it later” (Meyer, 2010, n.p). There needs to be a balance of both; where students are learning basic skills and are able to apply those skills in real life situations. By creating an atmosphere in the classroom where everyone learns the basic skills then when lessons are taught where students need to explore, everyone will be a beginner and student participation will create positive experiences.

Lastly, this topic relates directly to the current public conversation regarding Alberta Education and the changes they would like to make regarding the mathematics curriculum. The current curriculum is using discovery math teaching techniques instead of traditional formulas and memorization. Alphonso (2014) states,

Alberta and other provincial governments have been staunch defenders of discovery- or inquiry-based math, arguing it gives children broader problem-solving skills that are useful in everyday life. Instead of memorizing the multiplication tables or learning basic algorithms such as long division, students are encouraged to break problems down into smaller portions to work through them. (n.p)

Digital technologies and discovery math has been replacing traditional ways of teaching students math skills. Rather than students learning basic multiplication tables they are put in a real life problem solving situation. There needs to be a balance and Alberta Education is starting to 
reevaluate the current curriculum. By teaching children the basics first and then showing them the relevant situations creates much broader learning experiences.

This topic has been explored but there has not been a concrete way of teaching mathematics and Alberta Education is still trying to find the answer. Research tends to agree with creating a link to real life with mathematics for students. Teachers need to have a full understanding of how to use technologies properly; however, they are not being taught in university. Kirkwood (2000) states, "Even in those universities that have technology education programs, most undergraduates do not take a required course in technology concepts” (n.p). Teachers need to be taught how to use technology to integrate it properly. Furthermore, teachers need to use technology as an assistive tool much like math manipulatives rather than allowing technology to replace lessons and student fluency in math. Edyburn (2003) states "manipulatives are abandoned as students gain fluency and automaticity in problem solving. Calculators and computers are sometimes simply considered to be another form of math manipulative” (p. 77). Mathematics is an essential subject that needs to be taught to students' at the most optimal times to give them the understanding for future success in life.

\section{Research Context}

I gathered data for my research study from students in the Bachelor of Education program at Mount Royal University, professors in the Education and Mathematics Departments, and practicing elementary teachers who are currently teaching mathematics. Most of the data was gathered in Calgary, Alberta. Participants were selected by various levels of experience with mathematics. This included education students who have experienced mathematics through their education journey, professors who have participated and taught mathematics courses, and teachers who have taught young children the current Alberta curriculum. All participants 
remained anonymous throughout this research project and were assured of this before taking part. Participants all participated willingly, they were told what the research was about and they did not need to feel obliged to participate.

\section{Methods of Investigation}

The methods of investigation to gather data for this research project included online surveys using yes/no, short and long answer questions, conducting interviews, and field notes. My general approach for research design was primarily qualitative based on a case study approach. This approach seemed to be the best fit for this research project because it is not a straightforward topic. It was important to include various participants such as professors, practicing teachers, and university students' perspectives and experiences in my research topic. Furthermore, including observations of real student experiences was important in understanding this topic. I chose to conduct online surveys first to discover the demographics of the people who were participating in my research (Appendix 1). I then chose to interview people to further clarify and understand their views on the research topic (Appendix 2). Taking field notes allowed me to view real situations where students were participating in various math lessons that were directly related to my research.

I organized the data using Google Drive and the Google Forms survey program. My interviews were recorded in an email and the field notes were in a Google Doc. I analyzed the data by comparing perspectives and common themes; by splitting the data and being able to copy and paste to various groupings it made it easy to see where the common perspectives regarding mathematics were more popular. Furthermore, I used word clouds, charts, and graphs to compare the data I had collected. Google Drive made it easy to have the information accessible at all times and even when first collecting data it was easy to have it all in one place. 
After analyzing the data gathered, it would have been beneficial to gain further information from practicing teachers in the field working with mathematics. It was difficult to gain the perspectives of teachers because the teachers I asked to interview said they would and then backed out at the last minute.

\section{Findings}

After collecting the results of the survey, I was able to start analyzing my findings and the significance they offered to this research. I conducted further interviews and field study after looking at the survey data and identifying areas that needed to be further looked at. Thirty-six people took part in my online survey; of those participants the majority was female (Figure 1). Of those people, I conducted further interviews.

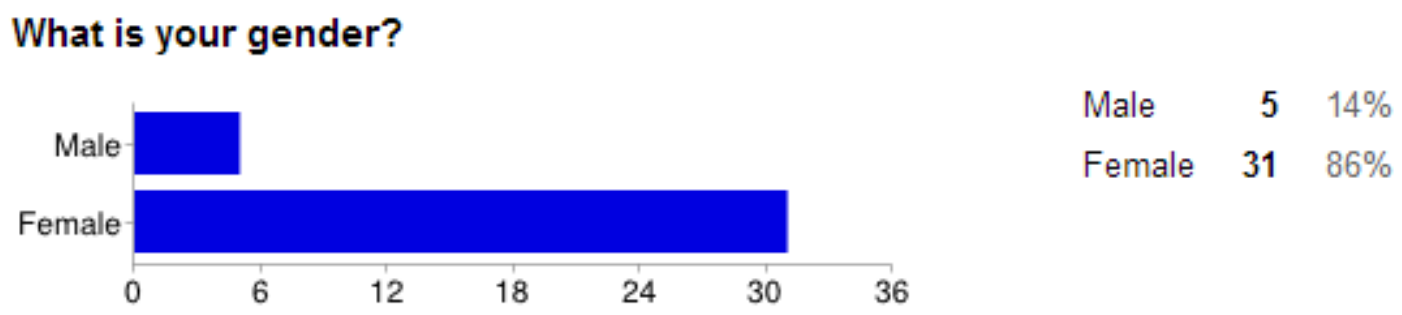

Figure 1. Gender of participants

There were many different professions that took part in my survey, although they are not equally distributed I believe insight will still be available through the information of all the participants (Figure 2). 
What is your profession?

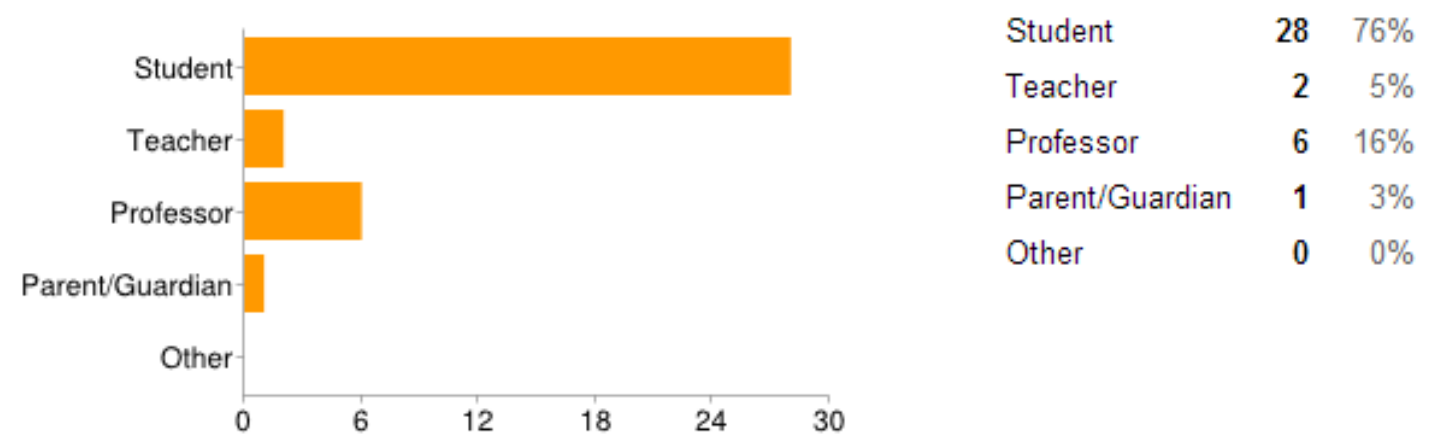

Figure 2. Profession of participants

A very important part of this research project was to find out if people had faced anxiety or phobias when dealing with math and the various causes of their positive and negative experiences. We know that people who face anxiety or phobias in mathematics will limit their learning experiences. This information excludes professors that were surveyed but out of all the other participants 67\% had faced anxiety in mathematics (Figure 3).

\section{Have you faced math anxiety?}

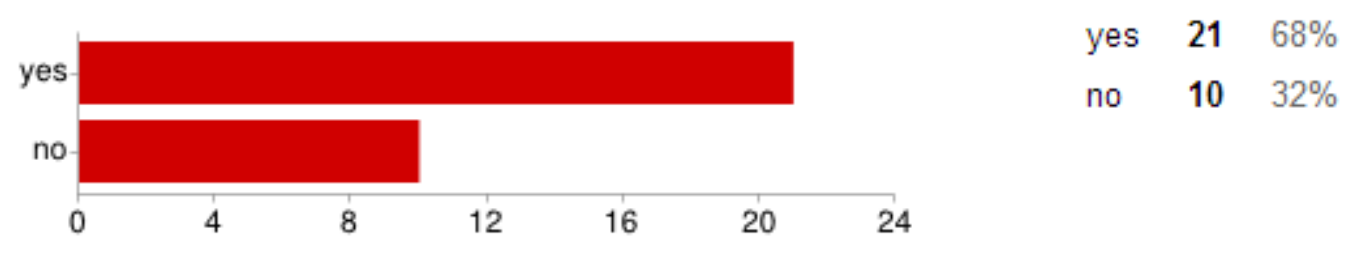

Figure 3. Participants who have faced math anxiety (excluding 6 professors)

The experiences students face in school when learning mathematics can have a lifelong effect on learning. I asked participants about the causes of positive experiences in mathematics and causes of negative experiences and anxiety and there were common themes found in both.

With regards to anxiety and negative experiences with mathematics, students had the common themes of not understanding, teachers, and curriculum content. Some of the responses 
overlap into the categories; however, these themes are very important to understand (Table 1).

Table 1

Major themes related to anxiety and negative experiences with mathematics

Not Understanding Teachers Curriculum Content

1. Just things from elementary school that I didn't pick up on as fast as other people. Then got insecure.

2. Not being able to comprehend or understand what is being asked.

3. Not understanding the topic

4. Not understanding it.

5. Lack of understanding and testing confusion

6. What caused it was not feeling very prepared

7. Being unprepared for exams I think that I was just not very good at math

8. Lack of knowledge and interest

9. Lack of understanding

10. We played a game which required students to be fast at multiplication, and I was not fast.
1. Teachers caused it by telling me that I am bad at math

2. My grade 12 teacher caused it due to his lack of professionalism and did not care about struggling students not understanding

3. I didn't have a competent teacher to teach me.

4. A teacher that didn't care.

5. My teacher was not very good and made me feel bad about myself for not being good at math

6. Bad teachers.

7. We played a game which required students to be fast at multiplication, and I was not fast. was not encouraged to be good at math its tough
1. In high school the work suddenly became much harder and I don't think I was prepared. I went from 90's to 60's not feeling prepared

2. The fact that it got too complicated specific topics covered.

There were also clear themes for the causes of positive experiences with mathematics. These included understanding, success, and practicality. These responses also overlapped in 
some areas (Table 2).

Table 2

Major themes related to positive experiences with mathematics

Understanding

1. The only time I kind of liked it was in junior high when I got decent grades because it wasn't as hard.

2. When I understood it I thought it was fun.

3. Loved it all

4. I was very bright in junior high and got to work on math independently of the class and was able to work ahead. It was nice to challenge myself.

5. I understood it well I like adding money

6. There is always a right answer

7. Understanding

8. When I was able to understand a concept
Success

1. I loved learning, and when I succeeded I felt great pride

2. In junior high I began to experience success with math.

3. I know how to do the 9 times table on my hands

4. Gr.10 math instruction was so well done that I didn't need anymore tutoring in math.

5. Passing math 30 barely

6. Success
Practicality

1. I really enjoyed math projects and things other than just doing questions.

2. Engaging in survey lessons, where we were able to go to different classes and survey students.

3. Physics in grade 8 was super fun.

4. I loved math up to grade 9. It was fun and hands on.

5. I love working with numbers and mathematical concepts because a lot of them are logical.

Not all classrooms use digital technologies. In the online survey I created, when participants were asked what the common tools were used in the classroom the majority gave traditional tools opposed to digital technologies. These included things like: chalkboards, textbooks, manipulatives, blocks, and whiteboards. The only digital technologies given were SMART Boards and calculators (Figure 4). 


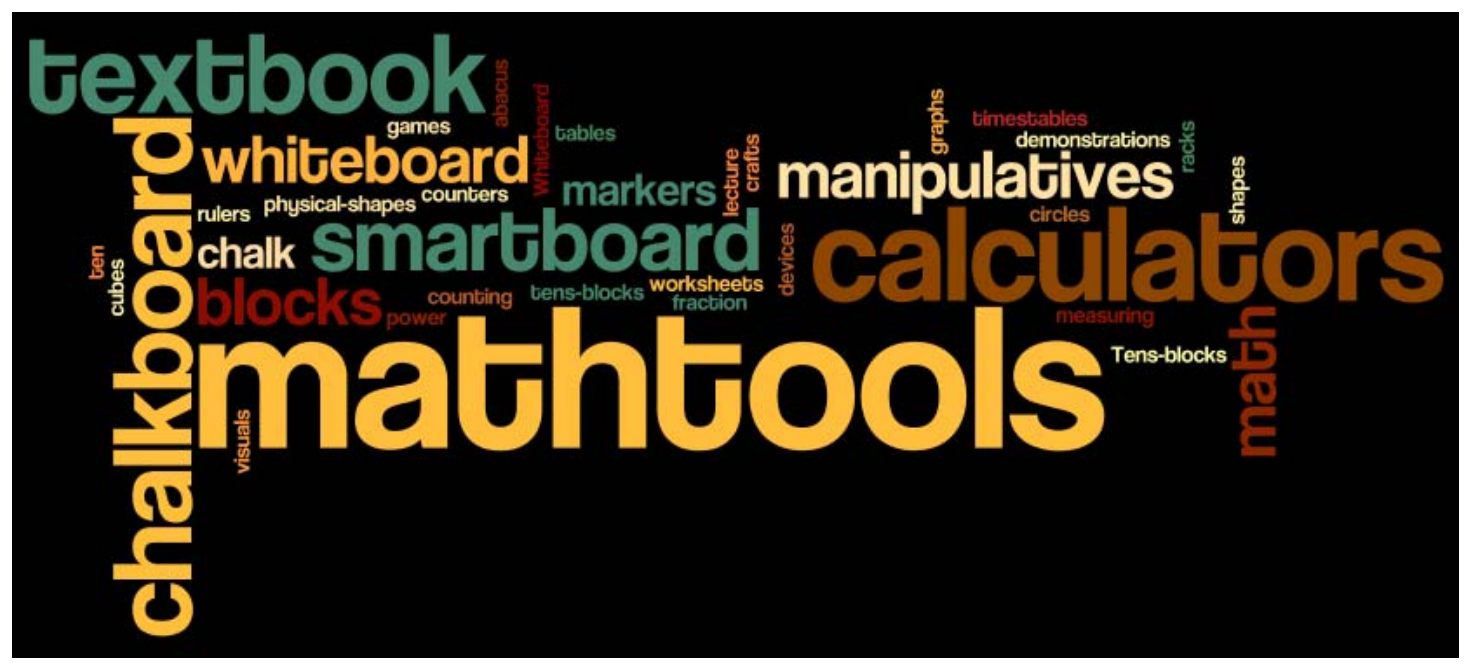

Figure 4. Common tools used in the mathematics classroom

By analyzing my open ended survey question, I identified the following four themes about the use of digital technologies in mathematics education:

1. Positive but . .

2. Struggling students

3. Start with the basics and use technology as an assistive tool

4. Not as much technology

With regards to the first theme, one professor participant commented that "[Digital Technologies are] excellent for visualizing, student convenience and for self conscious students to try to work through some concepts on their own. [However;] the two downsides: not as personal and in many universities technology is being used to facilitate jumbo classes and mass assess students” (Professor Participant 6).

A teacher participant stated that "Sometimes struggling students do not respond appropriately to technology" and that "Sometimes digital tools help, but if a student is struggling they often need 1 to 1 guidance from a person” (Teacher Participant 1).

Another professor indicated that "I'm skeptical of technological tools. I think that the 
basics are most important, and then giving the students time to work through problems with pen and paper is the most important thing” (Professor Participant 7). This sentiment was echoed by a teacher participant who stated "I feel like technology can compliment these strategies, but not replace them. The math programs (like Dreambox) use similar strategies to teach the students addition and subtraction but I still start the learning with using the hands on items. For some students, they like to use the math racks (the real ones) when they work on the computer" (Teacher Participant 1). In addition, this participant commented that "I do teach all the concepts before they are introduced on the computers. For example, the students learn about ten frames and work with them in the classroom and then I show the website ten frame illuminations” (Teacher Participant 1).

Finally, a professor participant stated that "I think that technology is overrated for the teaching of math. The most effective way to get students to overcome their anxiety is to provide a safe environment where they don't have to fear failure. You have to build their confidence with positive reinforcement, and perhaps one-on-one tutoring until they realize that they have the ability to learn math” (Professor Participant 7).

\section{Conclusion and Recommendations}

This research study has had a major impact on my future practice as a teacher. It has clearly demonstrated to me the importance of creating positive experiences for students by; designing relevant learning experiences, success and understanding for students, and being a positive role model as a teacher. It also is important that students are learning the basics and understanding content before moving on to relating content to real life, and more challenging experiences. In saying this, digital technologies need to be an assistive tool for teachers and should not replace hands on learning experiences. Teachers need to be trained and have a full 
understanding of the digital technologies they are using. Wolfram (2010) says, “correctly using computers is the silver bullet for making math education work” (p.5). Some teachers try to facilitate learning by using too much technology without really understanding if or how it is helping students.

Teachers need to create an environment where students are engaged in their learning. Meyer (2010) discusses, “five symptoms that you're doing math reasoning wrong in your classroom ... lack of initiative ... students don’t self start ... lack of perseverance ... lack of retention ... aversion to word problems ... eagerness for formula to apply” (p.8). Teachers need to be aware of these signs in their classroom in order to be sure students are really learning math rather than trying to only use simple base level skills. Digital technologies should not fully replace any math lessons; however, by having a balance of teaching the basics and applying those to real life situations, students will have a wholesome math learning journey.

My recommendations would be for teachers to keep in mind that they are the biggest factor in whether a student has a positive or negative experience in math. The consequences for negative experiences in math can lead to lifelong math anxiety for students. Positive experiences encourage and maximize student learning in mathematics. Furthermore, teachers need to teach their students the basics and then support those lessons with various technologies if it is appropriate. Lastly, in this study I asked for participant suggestions on digital tools, websites, and programs that can further assist with teaching math these can be found in Appendix 3.

This research project has made me question what further digital resources can be used for facilitating learners and to further experiment and learn how to use technological tools properly in the classroom. 


\section{References}

Alphonso, C. (2014, March 25). Parents push alberta curriculum back to math basics. The Globe and Mail. Retrieved from http://www.theglobeandmail.com/news/national/parents-pushalberta-back-to-math-basics/article17654746/

Edyburn, D. (2003). Measuring assistive technology outcomes in mathematics. Journal Of Special Education Technology, 18(4), 76-79.

Edyburn, D. L. (2008). Understanding what works and doing what works. Journal of Special Education Technology, 23(1), 59-62.

Jarvis, D., \& Naested, I. (2012). Exploring the math and art connection: Teaching between the lines. Calgary, Canada: Brush Education Incorporated.

Kirkwood, J. J. (2000). The status of technology education in elementary schools. Journal of Industrial Teacher Education, 37(3). Retrieved from http://scholar.lib.vt.edu/ejournals/JITE/v37n3/kirkwood.html

Li, Q., Lemieux, C., Vandermeiden, E., \& Nathoo, S. (2013). Are you ready to teach secondary mathematics in the 21st century? A study of pre-service teachers' digital game design experience. Journal of Research on Technology in Education, 45(4), 309-337.

Meyer, D. (2010, July). Dan Meyer: Math class needs a makeover [Video file]. Retrieved from http://www.ted.com/talks/dan_meyer_math_curriculum_makeover

Tuttle, H. (2008). Technology = Math Success. Technology \& Learning, 28(7), 30-32.

Wolfram, C. (2010, July). Conrad Wolfram: Teaching kids real math with computers [Video file]. Retrieved from http://www.ted.com/talks/conrad_wolfram_teaching_kids_real_math_with_computers 


\section{Appendix 1: Online Survey Questions}

1. What is your gender?

2. What is your profession?

3. Have you faced math anxiety?

4. What is your opinion on the importance of math?

5. If you faced math anxiety what do you believe caused it?

6. What were the difficulties you faced in your math classes during your school career?

7. What were your positive experiences with math?

8. What were some of the tools teachers used in your math classes?

9. Could any of these strategies been replaced with technological tools?

10. Are you familiar with any math tools to assist elementary classrooms?

11. Is there any specific technological tools that you are familiar with that have assisted you or someone you know in math?

12. What is your opinion on math technological tools affecting student interest, experiences, understanding and anxiety with math? 


\section{Appendix 2: Interview Questions}

1. How many years have you been teaching?

2. Is technology improving student experience in Math? If so, how? If not, why not?

3. Is technology improving student understanding in Math? If so, how? If not, why not?

4. Is technology improving student interest and motivation in Math? If so, how? If not, why not?

5. What affects/differences have you seen in your teaching and planning regarding technology and math?

6. What changes have you noticed between students or classes with technology and math?

7. Please expand on the strategies you said could be replaced by technology (abacus, math rack, manipulatives). Are there specific programs already in place to replace those?

8. How do you specifically use technology to teach math? (expand on programs you use with the Smart Board etc.)

9. What helps/creates positive experiences in math? You said success but is there anything more specific?

10. You said Dreambox and Kahn academy for resources. Were there any further resources for math that you know of for future teachers?

11. Do you agree or disagree, please explain:

a) Technology should be used after basic skills?

b) Technology should be used as an assistive tool or should almost replace teaching or other methods?

c) The only math taught (in all grades) should be relevant to real life? 


\section{Appendix 3: Assistive Tools for Mathematics using Digital Technology}

1. coolmathgames.com

2. mathisfun.com

3. coolmathforkids.com

4. khanacademy.com

5. Dreambox.com

6. scratch.com

7. mathworld.wolfram.com/

8. addition app

9. math tree app 